\title{
Construction of in vitro patient-derived tumor models to evaluate anticancer agents and cancer immunotherapy
}

\author{
NOBUHIKO TAKAHASHI ${ }^{1,2}$, ARISA HIGA ${ }^{1}$, GEN HIYAMA $^{1}$, HIROSUMI TAMURA ${ }^{1}$, HIROTAKA HOSHI $^{1}$, \\ YUU DOBASHI ${ }^{1}$, KIYOAKI KATAHIRA ${ }^{1}$, HIROYA ISHIHARA ${ }^{3}$, KOSUKE TAKAGI ${ }^{4}$, \\ KAZUHITO GODA $^{3}$, NAOYUKI OKABE ${ }^{5}$, SATOSHI MUTO ${ }^{5}$, HIROYUKI SUZUKI ${ }^{5}$, \\ KENJU SHIMOMURA ${ }^{2}$, SHINYA WATANABE ${ }^{1}$ and MOTOKI TAKAGI ${ }^{1}$ \\ ${ }^{1}$ Medical-Industrial Translational Research Center; ${ }^{2}$ Department of Bioregulation and Pharmacological Medicine, \\ Fukushima Medical University, Fukushima, Fukushima 960-1295; ${ }^{3}$ Research and Development, \\ Department of Biological Evaluation Technology 2; ${ }^{4}$ Research and Development, \\ Department of Technology Innovation 3, Olympus Corporation, Hachioji, Tokyo 192-8512; \\ ${ }^{5}$ Department of Chest Surgery, Fukushima Medical University School of Medicine, Fukushima, Fukushima 960-1295, Japan
}

Received December 20, 2020; Accepted February 22, 2021

DOI: $10.3892 / \mathrm{ol} .2021 .12667$

\begin{abstract}
An in vitro assay system using patient-derived tumor models represents a promising preclinical cancer model that replicates the disease better than traditional cell culture models. Patient-derived tumor organoid (PDO) and patient-derived tumor xenograft (PDX) models have been previously established from different types of human tumors to recapitulate accurately and efficiently their tissue architecture and function. However, these models have low throughput and are challenging to construct. Thus, the present study aimed to establish a simple in vitro high-throughput assay system using PDO and PDX models. Furthermore, the current study aimed to evaluate different classes of anticancer drugs, including chemotherapeutic, molecular targeted and antibody drugs, using PDO and PDX models. First, an in vitro high-throughput assay system was constructed using PDO and PDX established from solid and hematopoietic tumors cultured in 384-well plates to evaluate anticancer agents. In addition, an in vitro evaluation system of the immune response was developed using PDO and PDX. Novel cancer immunotherapeutic agents with marked efficacy have been used
\end{abstract}

Correspondence to: Professor Motoki Takagi, Medical-Industrial Translational Research Center, Fukushima Medical University, 1 Hikariga-oka, Fukushima, Fukushima 960-1295, Japan

E-mail: m-takagi@fmu.ac.jp

Abbreviations: PDO, patient-derived tumor organoid; PDX, patient-derived tumor xenograft; BiTEs, bispecific T-cell engagers; ADCC, antibody-dependent cellular cytotoxicity; CTLs, cytotoxic $\mathrm{T}$ lymphocytes; NK cells, natural killer cells; ALL, acute lymphocytic leukemia; AML, acute myeloid leukemia; LAK, lymphokine-activated killer; HTS, high-throughput screening

Key words: PDO, PDX, anticancer agents, molecular targeted drugs, antibody drugs, high-throughput in vitro assay, ex vivo assay, cancer immunotherapy, cancer immunity, immune response against various types of tumor. Thus, there is an urgent need for in vitro functional potency assays that can simulate the complex interaction of immune cells with tumor cells and can rapidly test the efficacy of different immunotherapies or antibody drugs. An evaluation system for the antibody-dependent cellular cytotoxic activity of anti-epidermal growth factor receptor antibody and the cytotoxic activity of activated lymphocytes, such as cytotoxic T lymphocytes and natural killer cells, was constructed. Moreover, immune response assay systems with bispecific T-cell engagers were developed using effector cells. The present results demonstrated that in vitro assay systems using PDO and PDX may be suitable for evaluating anticancer agents and immunotherapy potency with high reproducibility and simplicity.

\section{Introduction}

Historically, human cancer cell lines have been widely used to study cancer biology or as preclinical models to evaluate anti-cancer agents. However, these cell lines may not necessarily preserve the quality of their source tumor tissues' characteristics, because their genome sequence, gene expression profile, and morphology can change while passaging culture over long periods. Additionally, most of these cell lines are cultured in a monolayer or used as murine xenograft, neither of which are physically representative of tumor tissues $(1,2)$. Thus, the clinical efficacy of anti-cancer drugs is not identical to that obtained during evaluations in cancer cell lines. Approximately $85 \%$ of approved preclinical drugs tested in cancer clinical trials have not demonstrated sufficient efficacy or safety to warrant regulatory approval (3-5).

Patient-derived tumor xenograft (PDX) models have been used as preclinical cancer models since they closely mimic human cancer tissue (6-11). Increasing evidence suggests that PDX predicts patient response to drugs by being directly comparable to the corresponding cancer tissue. However, the evaluation of anti-cancer agents using these models is challenging due to 
their low throughput and high cost. Therefore, in vitro systems such as ex vivo assays using PDX, patient-derived tumor organoids (PDOs), or spheroid models that accurately recapitulate tissue architecture and function have been developed recently. These in vitro systems have been established for different types of tumor tissues (e.g., bladder, breast, brain, colon, endometrium, kidney, liver, lung, pancreatic, prostate, kidney, and stomach), and associated high-throughput assay systems for drug screening have also been developed (11-22). In addition, heterogeneous ex vivo organoid cultures of primary tumors obtained from patients or PDX have gained considerable traction in recent years due to the ease of culturing and its ability to maintain stromal cellular complexity (23-25). These models are expected to enhance our understanding of cancer biology and facilitate the evaluation of drug efficacy in vitro.

To date, we have constructed a series of novel PDOs from different tumor tissue types under the Fukushima Translational Research Project, designated as F-PDO. F-PDOs form large cell clusters with a morphology similar to the original tumor and can be cultured for more than six months (26). In addition, our comparative histological and comprehensive gene expression analyses have shown that the characteristics of F-PDOs were similar to their source tumors, even after long-term growth in culture conditions. Moreover, we have generated a novel series of PDX models from numerous cancer tissues, including hematopoietic tumors, which we designated as Fukushima (F)-PDX. F-PDX models also have similar characteristics to their source tissue. Furthermore, we have constructed suitable high-throughput assay systems for each F-PDO in 96- and 384-well plates. We used these assay systems to evaluate several molecular targeted drugs and antibody drugs. Lastly, we analyzed the changes in the higher-order structure of F-PDOs caused by anti-cancer drugs using the 3D cell analysis system (27). The evaluation of anti-cancer drugs using F-PDO-based in vitro assay systems was comparable to the evaluation of anti-cancer drugs in clinical use.

Immunotherapy is one of the most significant paradigm shifts in the history of cancer therapy. Immunotherapeutic approaches include adoptive cell therapies, monoclonal antibodies, immune checkpoint inhibitors, bispecific T-cell engagers (BiTEs), cytokines, and vaccines used against various cancers to date. However, immunotherapeutic approaches have resulted in a wide variation in the degree and duration of patient responses and adverse effects. Numerous cancers remain entirely refractory to immunotherapy (28-31); thus, further improvements are needed. Besides, there are currently several reports on the construction of assay systems for immunotherapeutic agents using PDO (32). However, to our knowledge, there are no reports of simple and high-throughput assay systems for drug screening. Although many efficient and simple in vitro assay systems are available for determining clinically efficacious immunotherapy potency, such as the chromium 51 release assay, cytokine release assay, flow cytometry-based detection of crucial biomarkers, lactate dehydrogenase release assay, these are limited in throughput and simplicity of use (33). To address this issue, we aimed to construct simpler and more accurate in vitro assays to evaluate anti-cancer drugs and immunotherapy potency using the F-PDO and F-PDX models, and predict the clinical efficacy of anti-cancer drugs.

\section{Materials and methods}

Compounds and antibodies. Twenty-one anti-cancer agents tested in this study (Table SI) were dissolved in dimethyl sulfoxide (final concentration; $20 \mathrm{mM}$ ) and stored at $-80^{\circ} \mathrm{C}$ until use. The purity and integrity of the agents were measured using ultra-performance liquid chromatography-mass spectrometry (Waters Corporation) as follows: a $1-\mu 1$ injection volume, a Waters CORTECS C18 column (particle size: $1.6 \mu \mathrm{m}$; column size: $2.1 \times 50 \mathrm{~mm}$; Waters Corporation), linear aqueous acetonitrile $(\mathrm{MeCN})$ gradient containing $0.1 \%$ formic acid $\left(5-90 \% \mathrm{MeCN}, 1.6 \mathrm{~min}\right.$; flow rate, $\left.1 \mathrm{ml} / \mathrm{min}, 40^{\circ} \mathrm{C}\right)$, and the components of the significant ultraviolet adsorption peaks were identified using mass spectrometry (Table SI).

Cetuximab and bevacizumab were obtained from Bristol Myers Squibb and Merck \& Co., respectively. Blinatumomab was provided by Amgen.

Cells. F-PDOs were established in our previous study (26), and three lung F-PDOs (RLUN001, RLUN021, and RLUN023), each established from a different patient, were used in this study. Patient-derived hematopoietic tumor cells were provided by Fukushima Medical University Hospital, the Japanese Pediatric Cancer Group ALL-R14 study, ProteoGenex, or AllCells. Peripheral blood mononuclear cells (PBMCs; HPBMC Peripheral Blood Mono, cry amp) were provided by LONZA. Natural killer (NK)-Lymphokine-activated killer (LAK) cells were produced from PBMCs using the AdoptCell-NK kit (Kohjin Bio), following the manufacturer's instructions. Cytotoxic T lymphocytes (CTLs) were cultured from PBMCs in the ALyS505N-175 medium (Cell Science and Technology Institute, Inc.) containing IL-2 using anti-CD-3 antibody-solidified flasks following the manufacturer's instructions. ADCC Bioassay Effector Cell V variant (High Affinity) was obtained from BPS Bioscience.

Cell culture. F-PDOs were cultured and maintained in $15 \mathrm{ml}$ of Cancer Cell Expansion Medium plus (Fujifilm Wako Pure Chemical, Ltd.) using ultra-low attachment $75 \mathrm{~cm}^{2}$ flasks (Corning, Inc.) at $37^{\circ} \mathrm{C}$ in a humidified incubator with $5 \% \mathrm{CO}_{2}$ according to previous reports $(26,27)$. The number and viability of cells were measured using trypan blue dye exclusion and the Vi-Cell XR Cell Viability Analyzer (Beckman Coulter).

PDX. These experiments were performed with the approval of the Institutional Animal Care and Use Committee of Fukushima Medical University. To produce F-PDX, immunodeficient NOG

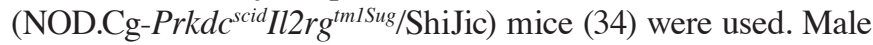
NOG mice (6- to 8-weeks old) were provided by the Central Institute for Experimental Animals (Kawasaki, Japan) and housed in plastic cages (136x208x115 mm) within a safety rack (CLEA Japan, Inc., Tokyo, Japan) in a pathogen-free state, at $22 \pm 2^{\circ} \mathrm{C}$ with $55 \pm 5 \%$ humidity and a 12 -h light/12-h dark cycle. The plastic cages, bedding, and filter caps sterilized in an autoclave or via gas sterilization were used. The mice could to feed ad libitum on a commercial $30 \mathrm{kGy}$ gamma-irradiated sterilized diet (CE-2; CLEA Japan, Inc.) and ultra-filtered membrane water. Hematopoietic tumor cells $\left(0.25-2.5 \times 10^{6}\right.$ cells $)$ were suspended in $0.3 \mathrm{ml}$ of Minimum Essential Medium $\alpha$ without nucleosides (cat. no. 12561056; Thermo Fisher Scientific, Inc.). They were injected via the tail vein of busulfan-treated or untreated mice. 
Proliferated tumor cells were extracted from the mouse spleen and bone marrow and frozen in CELLBANKER 1 (Zenoaq Resource) under liquid nitrogen until they were used for assays.

Cell viability assay. The cell viability assay for F-PDO was performed by modifying a method reported previously $(26,27)$. Three lung F-PDOs were minced using a CellPet FT (JTEC Corporation) with a filter holder containing a $70-$ or $100-\mu \mathrm{m}$ mesh filter. The cell clusters in each of the selected F-PDO suspension had sizes ranging from 140 to $160 \mu \mathrm{m}$, and 10 cell clusters per well were seeded into a 384-well, round-bottomed, ultra-low-attachment microplate (Corning, Inc.) in $40 \mu \mathrm{l}$ medium, using CELL HANDLER ${ }^{\mathrm{TM}}$ (Yamaha Motor). Twenty-four hours after seeding, F-PDOs were treated with $40 \mathrm{nl}$ of compound solutions at final concentrations ranging from $1.0 \mathrm{nM}$ to $20 \mu \mathrm{M}$, using a series of 10 concentrations (serially diluted 3-fold) using an Echo 555 Liquid Handler (Labcyte, Inc.). After 144 h, $10 \mu \mathrm{l}$ of the CellTiter-Glo 3D Cell Viability Assay kit solution (Promega Corporation) was added to F-PDOs in each well, and the plates were incubated for $15 \mathrm{~min}$ at $25^{\circ} \mathrm{C}$ after agitation of the plate using a mixer. Luminescence by luciferase was measured using the EnSpire Plate Reader (PerkinElmer, Inc.). Cell viability was calculated by dividing the ATP content in the test wells by that in the vehicle-control wells after subtracting the background levels. The 6-day growth rate was determined by dividing the ATP content in the wells without anti-cancer agents by those in the vehicle-control wells at $24 \mathrm{~h}$ after seeding.

Cell growth inhibition assays using hematopoietic tumor-derived PDX were performed in a similar manner as described above, except for the sample preparation. The frozen cells were thawed in a $37^{\circ} \mathrm{C}$ water bath and suspended in $10 \mathrm{ml}$ of RPMI-1640 medium (Fujifilm Wako Pure Chemicals, Ltd.) containing $10 \%$ fetal bovine serum (FBS) and penicillin/streptomycin, or Iscove's modified Dulbecco's medium (IMDM; Fujifilm Wako Pure Chemicals, Ltd.). The cells were centrifuged for $5 \mathrm{~min}$ at $400 \mathrm{xg}$. After removing the medium, the cells were resuspended in $15 \mathrm{ml}$ of RPMI-1640 medium or StemSpan Leukemic Cell Culture Kit (STEMCELL Technologies) corresponding to each PDX. The cells were then seeded at 0.5 or $1 \times 10^{4}$ cells per well in 384-well plates. Twenty-four hours after seeding, the cells were treated with anti-cancer agents for $48 \mathrm{~h}$, and a plate reader measured the ATP content.

The area under the activity curve (AUC) and half-maximal inhibitory concentration $\left(\mathrm{IC}_{50}\right)$ were calculated from the dose-response curves adjusted to the luminescence signal intensities using a 4-parameter sigmoid model or a sigmoidal fixed-slope model without the Hill equation and analyzed using Morphit software, version 6.0 (The Edge Software Consultancy, Ltd.). The data are presented as the average \pm standard deviation of triplicate experiments. The $\mathrm{Z}$-factor, a dimensionless parameter that ranges between 1 (infinite separation) and $<0$, was defined as $Z^{\prime}=1-\left(3 \sigma \mathrm{c}^{+}\right.$ $\left.+3 \sigma \mathrm{c}^{-}\right) / / \mu \mathrm{c}^{+}-\mu \mathrm{c}^{-1}$, where $\sigma \mathrm{c}^{+}, \sigma \mathrm{c}^{-}, \mu \mathrm{c}^{+}$and $\mu \mathrm{c}^{-}$are the standard deviations $(\sigma)$ and averages $(\mu)$ of the high $\left(\mathrm{c}^{+}\right)$and low $\left(\mathrm{c}^{-}\right)$controls (35). Cluster analysis was conducted using the unweighted pair group method with the arithmetic mean hierarchical clustering method by TIBCO Spotfire software, version 7.11 (TIBCO Software Inc.).

Antibody-dependent cellular cytotoxicity (ADCC) assay using reporter cells. ADCC Bioassay Effector Cell expressing a firefly luciferase gene was thawed in RPMI-1640 medium
(Fujifilm Wako Pure Chemical, Ltd.) containing 10\% FBS and penicillin-streptomycin and cultured in a $5 \% \mathrm{CO}_{2}$ incubator at $37^{\circ} \mathrm{C}$. The medium was changed to the growth medium containing $1 \mathrm{mg} / \mathrm{ml}$ Geneticin and $200 \mu \mathrm{g} / \mathrm{ml}$ Hygromycin B (Fujifilm Wako Pure Chemical, Ltd.) after the first passage, following the manufacturer's instructions.

Minced RLUN021 using CellPet FT with a $100-\mu \mathrm{m}$ mesh filter was diluted 2.5- or 5-fold using Cancer Cell Expansion Medium plus, and $20 \mu \mathrm{l}$ of the suspension was seeded in 384-well black plates (Greiner Bio-One GmbH). Subsequently, $10 \mu 1$ of the cetuximab solution was added to RLUN021 at a final concentration of 1,10 or $100 \mu \mathrm{g} / \mathrm{ml}$. During the incubation of RLUN021 with cetuximab, the medium of the ADCC Bioassay Effector Cell, a reporter effector cell line, was changed to Cancer Cell Expansion Medium plus. The reporter effector cells were then seeded at $5 \times 10^{4}$ cells per well $60 \mathrm{~min}$ post-antibody treatment. After $5 \mathrm{~h}$, the luminescence was measured using the ONE-Glo Luciferase Assay System (Promega Corporation) and the EnSpire Plate Reader.

Real-time potency assessment using the xCELLigence RCTA system. The xCELLigence RTCA System (ACEA Bioscience) was used to evaluate F-PDO's cytolysis with CTLs and NK cells. E-plate 96 (ACEA Bioscience), specifically designed to perform cell-based assays with the xCELLigence RTCA System, was coated with fibronectin solution $(0.5 \mu \mathrm{g} /$ well; Fujifilm Wako Pure Chemical, Ltd.) at $4^{\circ} \mathrm{C}$ overnight. After removing the fibronectin solution, $50 \mu \mathrm{l}$ of the culture medium was added to each well to measure the background impedance. Prior to seeding, RLUN021 was filtered through a $40-\mu \mathrm{m}$ cell strainer (Corning, Inc.). The cell suspension $(50 \mu \mathrm{l})$ were seeded at $2.5 \times 10^{3}$ cells per well in E-Plate 96 . The plate was incubated at approximately $24^{\circ} \mathrm{C}$ for $30 \mathrm{~min}$ and transferred to the xCELLigence RTCA instrument in a $\mathrm{CO}_{2}$ incubator at $37^{\circ} \mathrm{C}$. Each well contained a final volume of $100 \mu \mathrm{l}$. Forty-eight hours after seeding, $50 \mu \mathrm{l}$ of culture media was removed from each well, and $50 \mu \mathrm{l}$ of effector cell suspension was added at an effector: target cell ratio of 5:1 or 10:1. Changes in impedance signals were measured every $15 \mathrm{~min}$ as the cell index. Cytolysis values were converted from the cell index to percent cytolysis values using the xCELLigence immunotherapy software, version 2.3 (ACEA Bioscience). 'Percent cytolysis' refers to the proportion of target cells that were killed by effector cells compared to F-PDO alone as a control. The cell indexes of the wells containing only effector cells were subtracted from the index of the sample wells at each time point. Then, each value was normalized to the cell index immediately before antibody addition. The normalized index was converted to percent cytolysis according to the following equation: $\%$ cytolysis $=(1$-normalized cell index [sample wells] $) /$ normalized cell index (target alone wells) x100.

Three-dimensional cell analysis. Images were captured using a FLUOVIEW FV3000 Confocal Laser Scanning Microscope (Olympus) with a UCPLNFLN20X objective lens. All imaging data were analyzed using the NoviSight 3D Cell Analysis System (Olympus). NucView 530 Caspase-3 Substrate (Biotium, Inc, ) was used to quantify apoptotic cells. In detail, RLUN021 was suspended in Cancer Cell Expansion Medium plus containing $2 \mu \mathrm{M}$ NucView 530 Caspase-3 Substrate. The suspension $(100 \mu \mathrm{l})$ was seeded in a well of a 96-well, round-bottomed, 
ultra-low-attachment microplate (Corning, Inc.) and incubated for $30 \mathrm{~min}$ at $37^{\circ} \mathrm{C}$ in a $\mathrm{CO}_{2}$ incubator. After incubation, $50 \mu \mathrm{l}$ of the medium was removed from each well, and $50 \mu \mathrm{l}$ of the medium containing NK cells $\left(0.25,0.5,1.0\right.$ or $2.0 \times 10^{5}$ cells per well) were added into the well. The plate was incubated for $30 \mathrm{~min}$ and $3 \mathrm{~h}$ at $37^{\circ} \mathrm{C}$ in a $\mathrm{CO}_{2}$ incubator. Cells were then collected by centrifugation $(200 \mathrm{x} \mathrm{g}, 2 \mathrm{~min})$ and were fixed overnight at $4^{\circ} \mathrm{C}$ in a phosphate buffer solution containing 4\% paraformaldehyde (Fujifilm Wako Pure Chemical, Ltd.) and 1\% Triton X-100 (Fujifilm Wako Pure Chemical, Ltd.). Subsequently, the RLUN021 cells were washed twice with D-PBS (-), and the nucleus was stained with Hoechst 33342 (Dojindo Laboratories, Kumamoto, Japan) in D-PBS (-) for $30 \mathrm{~min}$ at approximately $20-25^{\circ} \mathrm{C}$. Finally, F-PDO was washed twice with D-PBS (-) and photographed under a microscope. In the NoviSight analysis, the nuclei in F-PDO were recognized with Hoechst 33342 signals. The dead cells were defined based on the NucView530 signals in the nucleus.

Cytotoxicity assay using calcein. CTL cells were cultured in ALyS505N-175 medium containing $175 \mathrm{IU} / \mathrm{ml}$ of IL-2 for 2 days. Frozen acute lymphocytic leukemia (ALL)-derived F-PDX cells were thawed in phenol red-free RPMI-1640 (Fujifilm Wako Pure Chemicals, Ltd.) on the day of the assays. The ALL cells were stained with $10 \mu \mathrm{M}$ membrane-permeant calcein-acetoxymethyl (calcein-AM; PromoCell $\mathrm{GmbH}$ ) for $30 \mathrm{~min}$ at $37^{\circ} \mathrm{C}$ and then washed twice with fresh medium. Twenty-five microliters of stained ALL cell suspension were seeded onto 96-well plates (Sumitomo Bakelite Co., Ltd.) at 3x10 $0^{4}$ cells per well. Next, CTL cells were centrifuged to change the medium from ALyS505N-175 to RPMI-1640, and $25 \mu 1$ of CTL cell suspension was added to each well at a CTL: ALL ratio of 5:1. Finally, 10 concentrations of blinatumomab from $1 \mathrm{pM}$ to $100 \mathrm{nM}$ were added to the CTL and ALL cell mixtures. Each well contained a final volume of $100 \mu \mathrm{l}$. The plates were incubated at $37^{\circ} \mathrm{C}$ for $2 \mathrm{~h}$ and then centrifuged for $5 \mathrm{~min}$ at $400 \mathrm{x} \mathrm{g}$. After $10 \mathrm{~min}$ of centrifugation, the wells of ALL cells without CTL cells and blinatumomab were treated with a lysis solution (Promega Corporation) to release all calcein from the stained ALL cells (cell lytic fluorescence of calcein-stained cells). Fifty microliters of the supernatant in all wells was transferred to a 96-well half-area black plate (Corning, Inc.). The fluorescence of calcein was measured at $\lambda_{\mathrm{ex}}=495 \mathrm{~nm}$ and $\lambda_{\mathrm{em}}=530 \mathrm{~nm}$ using the EnSpire Plate Reader. Dead cell ratio was defined as the fluorescence of dead ALL cells using blinatumomab (the test wells with antibody - the test wells without antibody)/fluorescence of total ALL cells (cell lytic fluorescence of calcein-stained cells-background fluorescence of calcein-stained cells) x100, expressed as a percentage.

Statistical analysis. Statistical analyses were performed with Microsoft Excel 2016 (Microsoft Corporation, Redmond, WA, USA), MEPHAS (http://www.gen-info.osaka-u.ac.jp/testdocs/ tomocom/mokuji1-e.html), xCELLigence immunotherapy software, version 2.3 or js-STAR XR version 1.0.3j (http://www. kisnet.or.jp/nappa/software/star/index.htm) software. Statistical differences between different test conditions were determined using one-way ANOVA followed by Dunnett's test. Holm test was used for multiple comparison with js-STAR XR software. Statistical significance was defined as $\mathrm{P}<0.05$ was considered statistically significant. The data are shown as means and the standard deviation from three or four replicate samples.

\section{Results}

Development of a cell growth inhibition assay using F-PDO. To evaluate anti-cancer agents using a patient-derived tumor model, we aimed to develop a high-accuracy and high-throughput screening (HTS) assay using F-PDOs and 384-well microplates. We have previously reported the construction of an HTS assay for each F-PDO (26,27). In this experiment, we further attempted to develop an accurate HTS assay by aligning the cell clusters' size to exclude cell debris from the assay system. We examined the use of F-PDO (RLUN001 and RLUN023) established from lung tumors, which is difficult to assay using reported methods. To seed the cell clusters in a 384-well plate, a cell picking and imaging system, CELL HANDLER ${ }^{\mathrm{TM}}$, which allows for accurate cell picking without damaging the cells, was used. HTS performance was evaluated by computing the coefficients of variation $(\mathrm{CV})$ and the $\mathrm{Z}$-factor. The $\mathrm{Z}$-factor has been widely accepted to validate assay quality and performance, and the assay is suitable for HTS if this value is $>0.5$ (35). The control data points in the 384-well plate assay showed little variability, with CV values of 5.4 and $6.4 \%$ and calculated Z'-factors of 0.84 and 0.81 , for RLUN001 and RLUN023, respectively (Table I). These results imply that this assay has high performance for HTS. In the method without CELL HANDLER ${ }^{\mathrm{TM}}$, CV values were 8.1 and $26.0 \%$, and the $Z$ '-factor values were 0.76 and 0.23 for RLUN001 and RLUN023, respectively (data not shown). Thus, the use of CELL HANDLER ${ }^{\mathrm{TM}}$ made it possible to perform assays with high accuracy, even when using 384-well plates.

To investigate the sensitivity of F-PDOs to anti-cancer agents using our HTS system, growth inhibition was assessed using RLUN001 and RLUN023 treated with eight anti-cancer agents, specifically, epidermal growth factor receptor (EGFR) inhibitors (erlotinib, gefitinib, afatinib, lapatinib, osimertinib, and rociletinib), and paclitaxel, which are standard clinical treatments for non-small cell lung cancer, and mitomycin $\mathrm{C}$ as a positive control. RLUN001 and RLUN023, which possess a sensitivity mutation (p.E746-A750del) to EGFR inhibitors, may indicate a high sensitivity. F-PDOs were treated with the drugs $24 \mathrm{~h}$ after seeding and were subsequently incubated for six days. The $\mathrm{IC}_{50}$ and $\mathrm{AUC}$ values of the anti-cancer agents in each F-PDO are shown in Table II. RLUN001 and RLUN023 showed high sensitivity $\left(\mathrm{IC}_{50}<250 \mathrm{nM}\right)$ to all EGFR inhibitors. We have previously reported that the $\mathrm{IC}_{50}$ values of erlotinib and gefitinib for RLUN021 without EGFR mutations were very high at $>20$ and $6 \mu \mathrm{M}$, respectively (27). These results indicate that an F-PDO with susceptibility mutations is highly sensitive to EGFR inhibitors, consistent with general clinical results (36).

Development of a cell growth inhibition assay using F-PDX. Conducting simple in vitro assays using PDX to evaluate anti-cancer drug candidates before conducting costly and time-consuming animal studies is desirable. In this study, we attempted to construct an HTS assay system using F-PDX derived from hematopoietic tumors. We constructed an in vitro assay system with 384-well plates using hematopoietic tumor-derived F-PDX: nine types of ALL-derived cells, six types of acute myeloid leukemia (AML)-derived cells, one type of multiple myeloma (MM)-derived cells, and two types of mixed phenotype acute leukemia (MPAL)-derived cells were used in the study. The growth rate of F-PDXs in 
Table I. High-throughput screening performance using F-PDO and F-PDX models.

\begin{tabular}{lccc}
\hline A, F-PDO & & & \\
\hline Model & Growth rate & CV, \% & Z'-factor \\
\hline RLUN001 & 2.6 & 5.4 & 0.84 \\
RLUN023 & 2.6 & 6.4 & 0.81 \\
\hline
\end{tabular}

B, F-PDX hematopoietic tumor

\begin{tabular}{lcrc}
\hline Model & Growth rate & CV, $\%$ & Z'-factor \\
\hline DLEU002 & 1.2 & 4.0 & 0.88 \\
DLEU003 & 1.6 & 12.2 & 0.63 \\
DLEU005 & 1.0 & 1.3 & 0.96 \\
DLEU006 & 1.0 & 3.7 & 0.88 \\
DLEU009 & 1.2 & 3.9 & 0.88 \\
DLEU012 & 1.0 & 2.0 & 0.94 \\
DLEU016 & 1.5 & 3.7 & 0.89 \\
DLEU026 & 1.7 & 3.2 & 0.90 \\
DLEU031 & 1.4 & 2.2 & 0.94 \\
DLEU011 & 1.3 & 4.5 & 0.87 \\
DLEU018 & 0.9 & 3.4 & 0.90 \\
DLEU020 & 1.1 & 4.7 & 0.86 \\
DLEU022 & 1.6 & 2.1 & 0.94 \\
DLEU027 & 1.4 & 3.1 & 0.91 \\
DLEU030 & 0.9 & 4.7 & 0.86 \\
DLEU013 & 1.4 & 7.8 & 0.77 \\
DLEU028 & 0.8 & 2.6 & 0.92 \\
DLEU029 & 1.1 & 4.0 & 0.88 \\
\hline CV is & &
\end{tabular}

$\mathrm{CV}$ is defined as the ratio of the standard deviation to the mean of the solvent control. CV, coefficient of variation; F-PDO, Fukushima-patient-derived tumor organoid; F-PDX, Fukushima-patient-derived tumor xenograft.

the plates was approximately 0.8 - to 1.7 -fold in two days of culture (Table I). As shown in Table I, CV and Z'-factor values were 1.3 to $12.2 \%$ and 0.63 to 0.96 , respectively. These results imply that this assay has satisfactory performance for HTS. To investigate the sensitivity of F-PDXs to anti-cancer agents using our HTS system, growth inhibition was assessed using treatment with 13 anti-cancer agents. The $\mathrm{IC}_{50}$ values of the anti-cancer agents in each F-PDX are shown in Tables III-V. The sensitivity of hematopoietic tumors to anti-cancer agents varied regardless of the type of cancer. In particular, the sensitivity of ALL cells to anti-cancer agents was significant.

Cluster analysis was performed for five ALL- and two AML-derived cancer cell lines and nine ALL- and six AML-derived F-PDX cells to determine sensitivity to anti-cancer drugs (Fig. 1). The sensitivity profiles of ALL and AML cells to anti-cancer drugs could not be distinguished. In contrast, the sensitivity profiling of cancer cell lines and F-PDX differed significantly. F-PDX was more resistant to anti-cancer drugs than cancer cell lines.

In vitro evaluation of ADCC with antibody drugs. We developed a simple system to measure ADCC activity using a
Table II. $\mathrm{IC}_{50}$ and $\mathrm{AUC}$ values of anticancer agents against each Fukushima-patient-derived tumor organoid model.

\begin{tabular}{lrrrrrr}
\hline & \multicolumn{2}{c}{ RLUN001 } & & \multicolumn{2}{c}{ RLUN023 } \\
\cline { 2 - 3 } \cline { 5 - 6 } Anticancer agent & $\mathrm{IC}_{50}, \mathrm{nM}$ & $\mathrm{AUC}$ & & $\mathrm{IC}_{50}, \mathrm{nM}$ & $\mathrm{AUC}$ \\
\hline Mitomycin C & 716 & 66 & & 201 & 175 \\
Paclitaxel & 3 & 383 & & 105 & 854 \\
Afatinib & 4 & 6 & & $<1$ & 52 \\
Lapatinib & 239 & 106 & & 168 & 247 \\
Erlotinib & 292 & 121 & & 186 & 353 \\
Gefitinib & 33 & 32 & & 15 & 433 \\
Osimertinib & 6 & 0 & & 5 & 367 \\
Rociletinib & 163 & 25 & 68 & 400 \\
\hline
\end{tabular}

AUC, area under the dose response curve.

patient-derived cancer model. ADCC is a defense mechanism involving cellular immunity. Immune effector cells have an active effect on the immune system cells that lyse cancer cells, whose membrane-surface antigens are bound by antibodies. The antibody's Fc region binds to effector cells (NK cells, monocytes, etc.) that have the Fc $\gamma \mathrm{R}$ receptor (Fc $\gamma \mathrm{RIIIa)}$. Therefore, effector cells are activated, and granzyme and other substances are released to lyse the target cells. To measure ADCC activity against F-PDO, we used the ADCC Bioassay Effector Cell as a reporter effector cell line and cetuximab, a monoclonal antibody targeting EGFR. RLUN021 cells, which have high expression levels of EGFR, were selected as the target cancer cells (27). The ADCC Bioassay Effector Cells were Jurkat $\mathrm{T}$ cells expressing firefly luciferase under the control of the nuclear factor of activated $\mathrm{T}$ cells response elements with constitutive expression of human Fc $\gamma$ RIIIa, a high affinity (V158) variant.

ADCC activity was measured as the luciferase activity from reporter effector cells. Because RLUN021 formed significant cell clusters and an accurate number of the cells could not be counted, it was challenging to determine the target cell: effector cell ratio. Therefore, we set two dilution conditions (2.5- and 5-fold) of target cells for the numbers of $5 \times 10^{4}$ effector cells. No luminescence was detected in RLUN021 cells alone or only incubated with effector cells. As expected, when RLUN021 diluted 2.5-fold were incubated with cetuximab for $1 \mathrm{~h}$ and then were treated with effector cells for $5 \mathrm{~h}$, a significantly high level of luminescence was observed that referred to ADCC activity (Fig. 2A). Even though ADCC activity was decreased with an increase in dilution rate of the target cells, its levels were higher than those in the effector cells alone (white bars). No ADCC activity was observed even with $100 \mu \mathrm{g} / \mathrm{ml}$ bevacizumab (anti-VEGF antibody) as a negative control compared with the effector cells alone group (Fig. 2B).

Immune response activity using CTL and $N K$ cells. To investigate the cytolysis of F-PDO with CTL and NK cells using the xCELLigence system, which monitor the number, morphology, and attachment of cells for a long duration, changes in impedance signals (cell index) were assessed using 
Table III. IC $_{50}$ values of anticancer agents against each ALL-derived F-PDX model.

\begin{tabular}{|c|c|c|c|c|c|c|c|c|c|}
\hline $\begin{array}{l}\text { ALL-derived } \\
\text { F-PDX } \\
\text { Medium }\end{array}$ & $\begin{array}{l}\text { DLEU002 } \\
\text { RPMI }\end{array}$ & $\begin{array}{l}\text { DLEU003 } \\
\text { StemSpan }\end{array}$ & $\begin{array}{c}\text { DLEU005 } \\
\text { RPMI }\end{array}$ & $\begin{array}{l}\text { DLEU006 } \\
\text { RPMI }\end{array}$ & $\begin{array}{l}\text { DLEU009 } \\
\text { RPMI }\end{array}$ & $\begin{array}{c}\text { DLEU012 } \\
\text { RPMI }\end{array}$ & $\begin{array}{l}\text { DLEU016 } \\
\text { RPMI }\end{array}$ & $\begin{array}{l}\text { DLEU026 } \\
\text { RPMI }\end{array}$ & $\begin{array}{l}\text { DLEU031 } \\
\text { StemSpan }\end{array}$ \\
\hline \multicolumn{10}{|l|}{ Anticancer agent } \\
\hline Prednisolone & 0.165 & $>20$ & $>20$ & 0.183 & 0.045 & 0.234 & 0.038 & $>20$ & 1.656 \\
\hline Cytarabine & 0.833 & 2.632 & 15.210 & $>20$ & 4.868 & 3.312 & 0.015 & $>20$ & 0.263 \\
\hline Doxorubicin & 0.019 & 0.385 & 0.034 & 0.020 & 0.041 & 0.105 & 0.017 & 1.092 & 0.064 \\
\hline Mitoxantrone & 0.001 & 0.191 & 0.002 & 0.001 & 0.002 & 0.037 & 0.001 & 0.189 & 0.005 \\
\hline Bleomycin & 9.760 & $>20$ & 9.991 & 0.146 & 0.151 & $>20$ & 3.785 & $>20$ & 5.103 \\
\hline Clofarabine & 0.045 & $>20$ & 0.069 & $>20$ & 0.039 & $>20$ & 0.024 & $>20$ & 0.040 \\
\hline Dasatinib & 4.647 & $>20$ & 11.144 & 0.069 & 3.047 & 19.186 & 0.361 & $>20$ & $>20$ \\
\hline Daunorubicin & 0.004 & 0.164 & 0.012 & 0.004 & 0.009 & 0.194 & 0.006 & 0.431 & 0.025 \\
\hline Idarubicin & 0.002 & 0.119 & 0.006 & 0.002 & 0.004 & 0.056 & 0.004 & 0.090 & 0.013 \\
\hline Tretinoin & $>20$ & $>20$ & $>20$ & $>20$ & $>20$ & 17.978 & 14.233 & $>20$ & $>20$ \\
\hline Vincristine & 0.012 & 0.822 & 0.032 & 17.235 & 0.028 & 0.125 & 0.001 & $>20$ & 0.114 \\
\hline Imatinib & 19.322 & $>20$ & $>20$ & 16.640 & 14.286 & $>20$ & 13.756 & $>20$ & $>20$ \\
\hline Nelarabine & $>20$ & $>20$ & $>20$ & $>20$ & $>20$ & $>20$ & $>20$ & $>20$ & $>20$ \\
\hline
\end{tabular}

$\mathrm{IC}_{50}$ values are indicated in $\mu \mathrm{M}$. F-PDX, Fukushima-patient-derived tumor xenograft; ALL, acute lymphocytic leukemia.

Table IV. $\mathrm{IC}_{50}$ values of anticancer agents against each AML-derived F-PDX model.

\begin{tabular}{|c|c|c|c|c|c|c|}
\hline $\begin{array}{l}\text { AML-derived } \\
\text { F-PDX } \\
\text { Medium }\end{array}$ & $\begin{array}{l}\text { DLEU011 } \\
\text { RPMI }\end{array}$ & $\begin{array}{c}\text { DLEU018 } \\
\text { RPMI }\end{array}$ & $\begin{array}{c}\text { DLEU020 } \\
\text { RPMI }\end{array}$ & $\begin{array}{l}\text { DLEU022 } \\
\text { RPMI }\end{array}$ & $\begin{array}{c}\text { DLEU027 } \\
\text { RPMI }\end{array}$ & $\begin{array}{c}\text { DLEU030 } \\
\text { RPMI }\end{array}$ \\
\hline \multicolumn{7}{|l|}{ Anticancer agent } \\
\hline Prednisolone & $>20$ & $>20$ & $>20$ & $>20$ & $>20$ & $>20$ \\
\hline Cytarabine & 1.358 & 0.736 & 0.620 & 0.444 & 0.610 & 2.179 \\
\hline Doxorubicin & 0.301 & 0.256 & 0.173 & 0.049 & 0.098 & 0.145 \\
\hline Mitoxantrone & 0.115 & 0.014 & 0.015 & 0.002 & 0.003 & 0.003 \\
\hline Bleomycin & $>20$ & $>20$ & $>20$ & 12.296 & $>20$ & 17.597 \\
\hline Clofarabine & 0.118 & 0.032 & 0.275 & 0.235 & 0.048 & $>20$ \\
\hline Dasatinib & $>20$ & 9.519 & 0.013 & 10.736 & 1.695 & 16.752 \\
\hline Daunorubicin & 0.085 & 0.037 & 0.068 & 0.014 & 0.022 & 0.019 \\
\hline Idarubicin & 0.040 & 0.014 & 0.021 & 0.005 & 0.006 & 0.006 \\
\hline Tretinoin & $>20$ & $>20$ & $>20$ & $>20$ & $>20$ & $>20$ \\
\hline Vincristine & 0.025 & 0.178 & 0.052 & 0.002 & 0.128 & 0.424 \\
\hline Imatinib & $>20$ & 17.621 & 5.134 & $>20$ & $>20$ & 16.372 \\
\hline Nelarabine & $>20$ & $>20$ & $>20$ & $>20$ & $>20$ & $>20$ \\
\hline
\end{tabular}

$\mathrm{IC}_{50}$ values are indicated in $\mu \mathrm{M}$. F-PDX, Fukushima-patient-derived tumor xenograft; AML, acute myeloid leukemia.

RLUN021 treated with CTL and NK cells in 96-well plates. RLUN021 had a high expression of the major histocompatibility complex (MHC) class I chain-related gene A (MICA). MICA, expressed on cancer cells, binds to the receptor for MICA/B and NKG2D (CD314) on NK cells, and the NK cells subsequently cause cytotoxicity in cancer cells (37). Therefore, RLUN021 is suitable for the measurement of cytolysis with NK cells. PBMCs are cultured with IL-2 to induce LAK cells that cause cytotoxicity. No tumor antigen stimulation is required to induce LAK cells. LAK cells are not defined by MHC and widely induce immune cell-mediated cytotoxicity against tumor cells. LAK cells are a heterogeneous population of killer cells primarily divided into two groups: CTL and NK cells, which are not restricted to MHC. Thus, RLUN021 was treated with CTL and NK cells. Compared to target cell alone, following treatment with 1:5 (Fig. 3A and C) and 1:10 (Fig. 3B and D) ratios of F-PDO cells to effector cells, NK cells immediately suppressed an increase in cell 


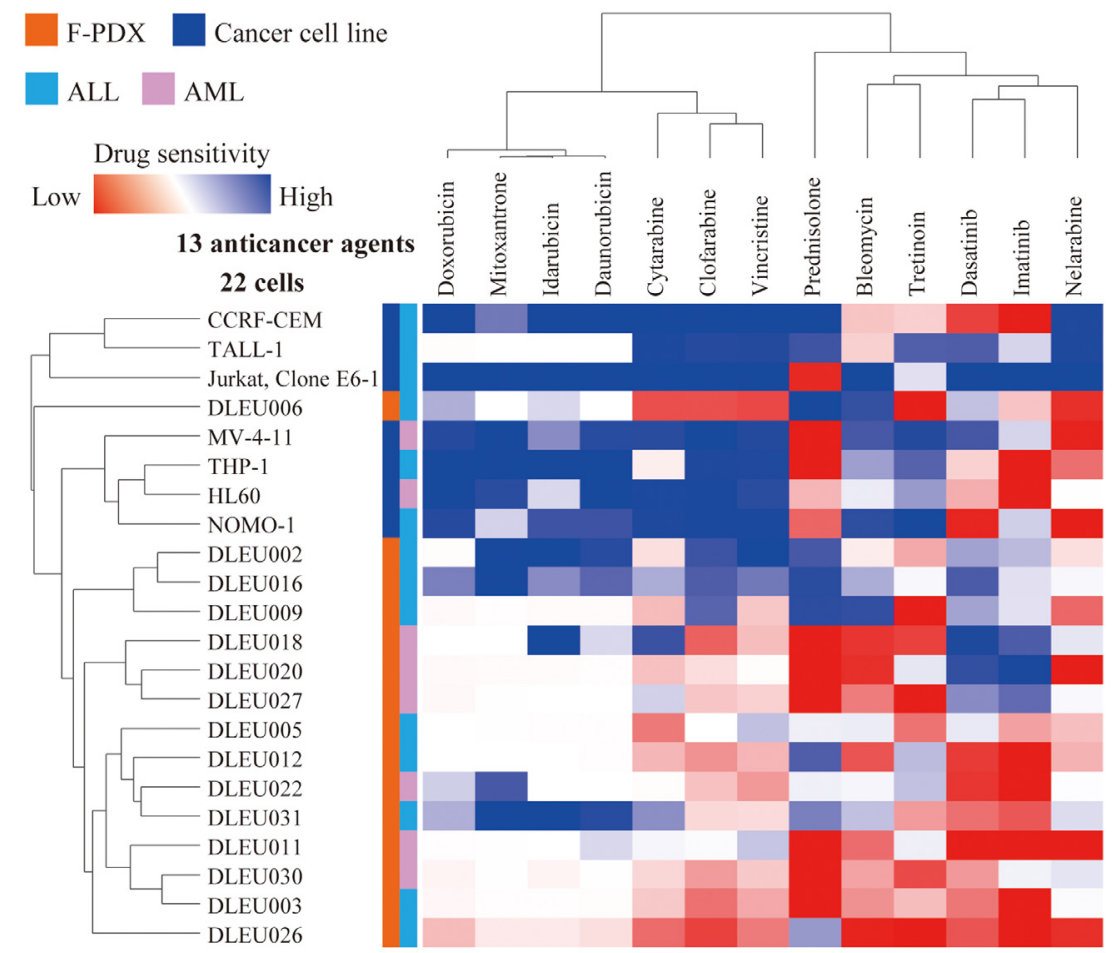

Figure 1. Cluster analysis of anticancer drug sensitivity. Cluster analysis findings based on the area under the activity curve values of five ALL- and two AML-derived cancer cell lines and nine ALL- and six AML-derived F-PDX cells to evaluate their sensitivity to 13 anticancer drugs. ALL, acute lymphocytic leukemia; AML, acute myeloid leukemia; F-PDX, Fukushima-patient-derived tumor xenograft.

Table V. $\mathrm{IC}_{50}$ values of anticancer agents against MM- and MPAL-derived F-PDX models.

\begin{tabular}{lccc}
\hline $\begin{array}{l}\text { F-PDX } \\
\text { Medium }\end{array}$ & $\begin{array}{c}\text { DLEU013 } \\
\text { StemSpan }\end{array}$ & $\begin{array}{c}\text { MPAL/ } \\
\text { DLEU28 } \\
\text { RPMI }\end{array}$ & $\begin{array}{c}\text { MPAL/ } \\
\text { DLEU029 } \\
\text { StemSpan }\end{array}$ \\
\hline Anticancer agent & & & \\
Prednisolone & $>20$ & 0.022 & $>20$ \\
Cytarabine & 7.548 & 3.986 & 0.551 \\
Doxorubicin & 0.041 & 0.022 & 0.037 \\
Mitoxantrone & 0.071 & 0.002 & 0.002 \\
Bleomycin & 19.556 & 0.775 & 1.649 \\
Clofarabine & 4.287 & 0.528 & 0.029 \\
Dasatinib & 0.990 & 14.456 & $>20$ \\
Daunorubicin & 0.031 & 0.006 & 0.017 \\
Idarubicin & 0.031 & 0.004 & 0.005 \\
Tretinoin & $>20$ & $>20$ & $>20$ \\
Vincristine & 0.028 & 0.026 & 0.072 \\
Imatinib & $>20$ & 9.831 & $>20$ \\
Nelarabine & $>20$ & $>20$ & $>20$ \\
\hline
\end{tabular}

$\mathrm{IC}_{50}$ values are indicated in $\mu \mathrm{M} . \mathrm{MM}$, multiple myeloma; MPAL, mixed phonotype acute leukemia; F-PDX, Fukushima-patient-derived tumor xenograft.

index (Fig. 3A and B). NK cell-mediated cytolysis was approximately 50 and $30 \%$ at a ratio of 10:1 (Fig. 3D) and 5:1 (Fig. 3C), respectively, after $12 \mathrm{~h}$.
In contrast, CTL-mediated cytolysis was slower, and approximately $10 \%$ of the cells were lysed at $12 \mathrm{~h}$ (Fig. 3C and D). There was also no significant difference in cytolysis induction when the number of effector cells was doubled (Fig. 3). These results indicate that the F-PDO assay system can evaluate immune response activity using real-time impedance-based technology.

To quantify the induction of cell death, we subsequently observed the cytolysis of RLUN021 by NK cells as an indicator of caspase-3 activation caused by the induction of apoptosis on cytolysis. Thirty minutes after NK cells treatment, apoptotic cells were not detected in cell clusters (Fig. 4). After $3 \mathrm{~h}$, apoptosis was observed in approximately $70 \%$ of the RLUN021 cells treated with $2 \times 10^{5} \mathrm{NK}$ cells per well. Meanwhile, apoptosis was observed in approximately $50 \%$ of RLUN021 treated with $1.0 \times 10^{5} \mathrm{NK}$ cells per well. However, RLUN021 treated with 0.25 or $0.5 \times 10^{5} \mathrm{NK}$ cells per well did not showed significant difference compared to the no NK cells treatment group. Thus, apoptosis was induced depending on the number of NK cells treated. These results were consistent with the results using the xCELLigence system.

Immune response of BiTE using F-PDX. A bispecific antibody, blinatumomab, and a patient-derived tumor model, ALL-derived F-PDXs, were used to construct a BiTE assay system. Blinatumomab is a bispecific antibody drug approved in 2014 for the treatment of B cell-derived ALL. Blinatumomab simultaneously binds to CD19 on the surface of B cells and CD3 on the surface of CTL cells. It causes cytotoxicity to ALL cells by engaging CTL cells with ALL cells. Six kinds of ALL-derived F-PDXs (DLEU001, 002,003, 004, 005, 016) and CTL cell mixtures were treated with blinatumomab (Fig. 5). 
A

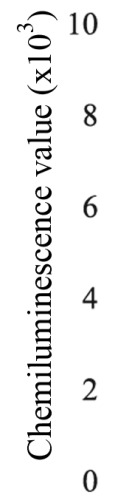

Cetuximab -

$(\mathrm{mg} / \mathrm{ml})$
$\mathrm{B}$

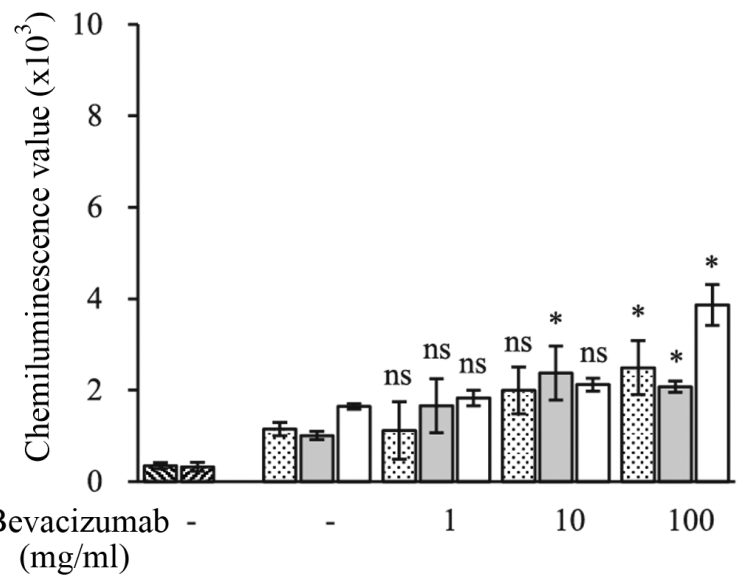

\footnotetext{
RLUN021 (diluted 2.5-fold)

范 RLUN021 (diluted 5-fold)

RLUN021 (diluted 2.5-fold) with ADCC bioassay effector cell

RLUN021 (diluted 5-fold) with ADCC bioassay effector cell

ADCC bioassay effector cell
}

Figure 2. ADCC activity against RLUN021. (A) Cetuximab and (B) bevacizumab. The vertical axis indicates the emission value. The activity was measured $5 \mathrm{~h}$ after the addition of the effector cells. The data are presented as the mean \pm SD of three replicate samples. ${ }^{*} \mathrm{P}<0.05$ vs. each group without antibody (A, RLUN021 with ADCC Bioassay Effector Cell or ADCC Bioassay Effector Cell without cetuximab; B, RLUN021 with ADCC Bioassay Effector Cell or ADCC Bioassay Effector Cell without bevacizumab), calculated by Dunnett's test after one-way ANOVA. ns, not significant; ADCC, antibody-dependent cellular cytotoxicity.

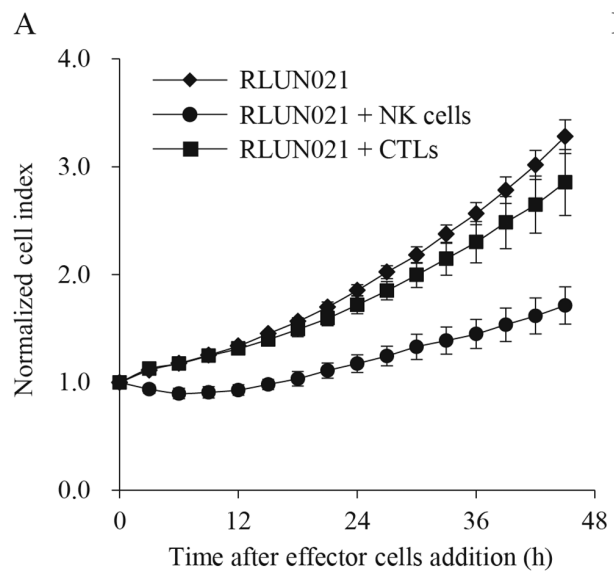

$\mathrm{C}$

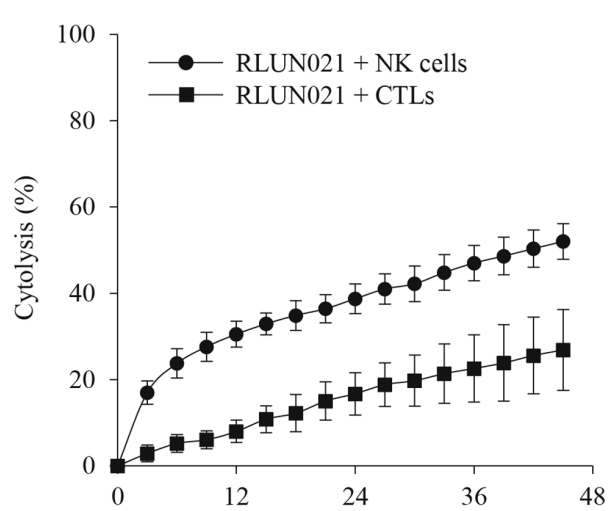

Time after effector cells addition (h)

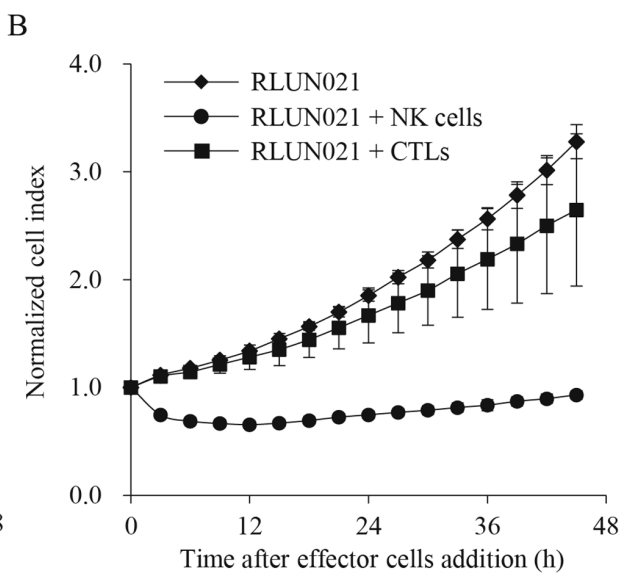

$\mathrm{D}$

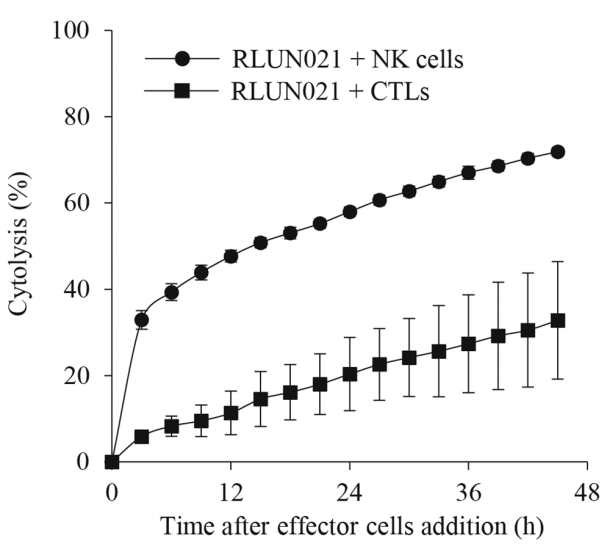

Figure 3. Impedance measurements of RLUN021 by effector cells. (A) Cell index (impedance) with ratio of RLUN021:effector cells of 1:5. (B) Cell index (impedance) with ratio of RLUN021:effector cells of 1:10. (C) Cell cytolysis with ratio of RLUN021:effector cells of 1:5. (D) Cell cytolysis with ratio of RLUN021:effector cells of 1:10. Dynamic changes in the cell index values were recorded over time. The data are presented as the mean \pm SD from three replicate samples. NK cells, natural killer cells; CTLs, cytotoxic T lymphocytes. 
A
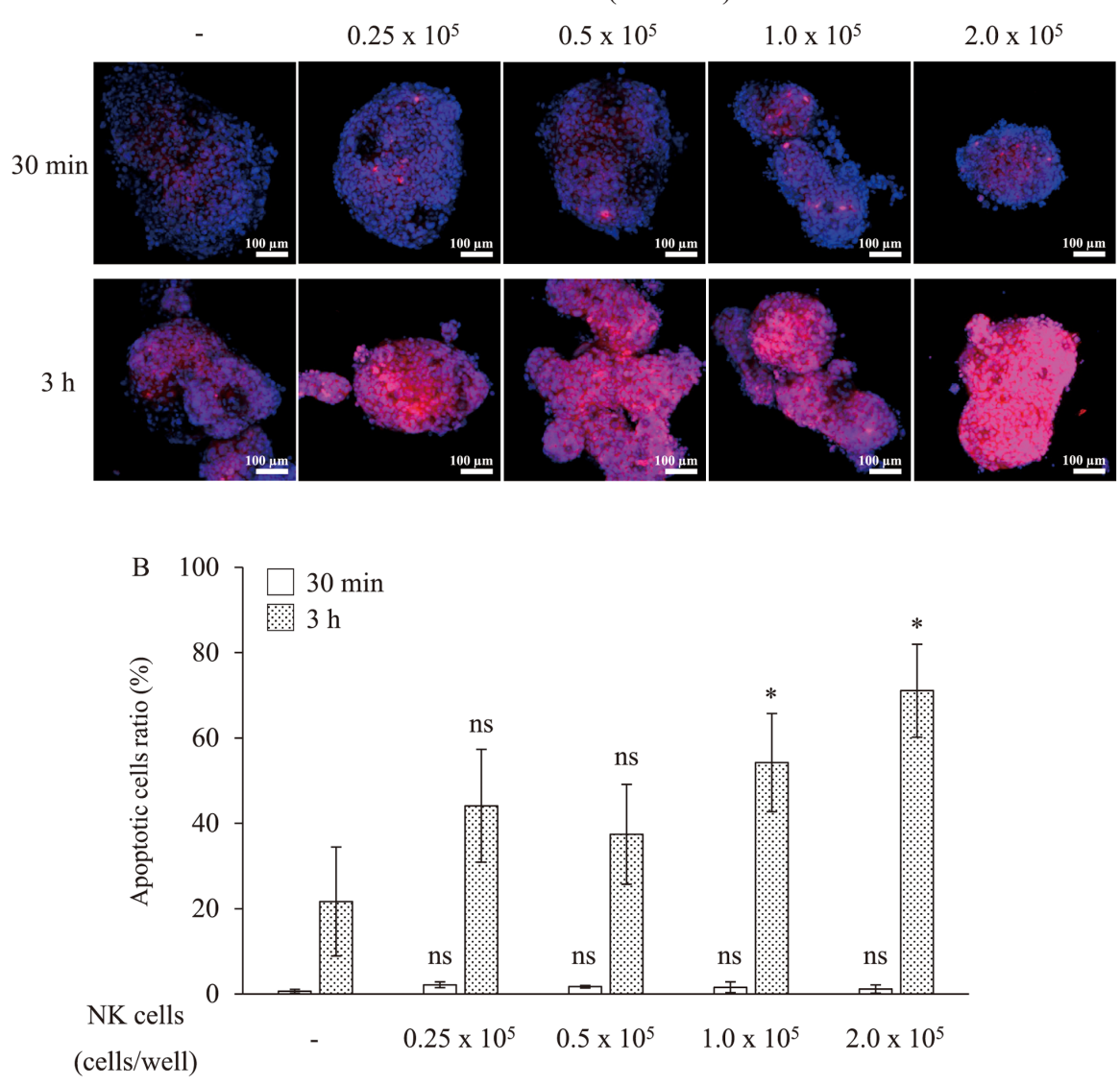

Figure 4. Apoptotic cells of RLUN021 cell clusters during cytolysis. (A) Representative images of apoptosis. Magnification, x20. Scale bar, $100 \mu \mathrm{m}$. Activated caspase-3 stained with NucView 530 is shown in red. DNA stained with Hoechst 33342 is shown in blue. (B) Ratio of the number of apoptotic cells per cell count (nuclei). The data are presented as the mean $\pm \mathrm{SD}$ of four cell clusters. ${ }^{*} \mathrm{P}<0.05$ vs. no NK cell treatment group, calculated using the Holm test. ns, not significant; NK cells, natural killer cells.
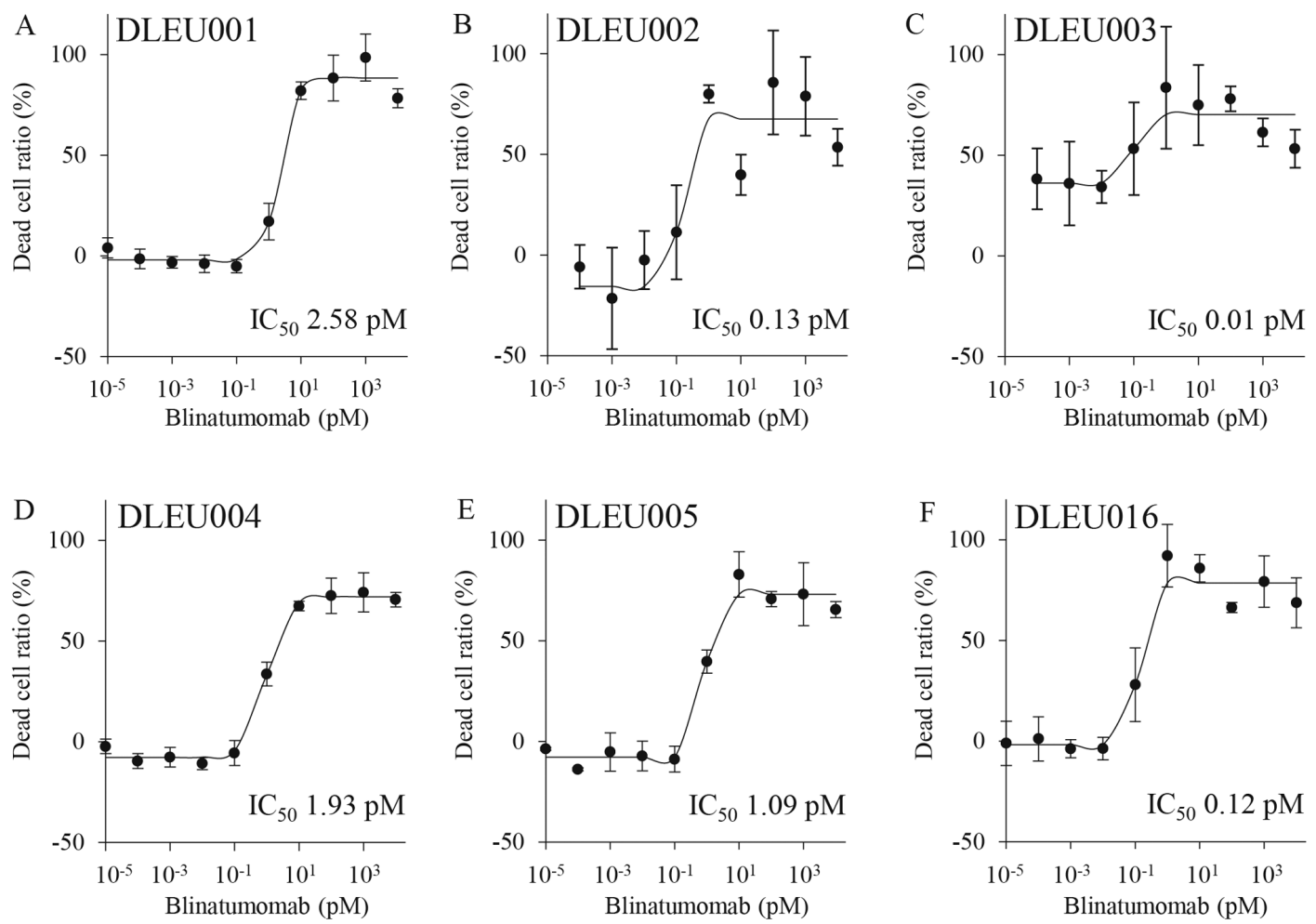

Figure 5. Cytotoxic activity against ALL cells with blinatumomab. The graphs represent the dose-response curves of ALL cells to blinatumomab. The data are presented as the mean \pm SD from triplicate experiments. ALL, acute lymphocytic leukemia. 
The data points for dead cells showed little variation and low $\mathrm{CV}$ values. The assay system was stable and satisfactory as an evaluation system for BiTE. Because all the ALL cells used in this experiment were CD19 positive, blinatumomab induced cell death in all ALL cells and showed low $\mathrm{IC}_{50}$ values (approximately 0.01-3 pM). It was interesting to observe that there was a difference in the effect of blinatumomab despite the lack of significant differences in the expression of CD19 in ALL cells. There may be differences in susceptibility to CTLs owing to varying patient characteristics.

\section{Discussion}

Here, we have developed a high accuracy and throughput assay system for anti-cancer drug evaluation using patient-derived models, F-PDO and F-PDX. Recently, in vitro assays using PDO and PDX have been reported (11-23). These culture and assays use extracellular matrixes such as Matrigel ${ }^{\circledR}$ to create tumor tissue scaffolds or enzymes such as trypsin and collagenase to disrupt the organs. Organoid cancer models $(15,38)$, widely available from the American Type Culture Collection in support of the Human Cancer Models Initiative, also use extracellular matrix and enzymes. There are few reports of HTS systems using PDO with 384-well plates, and these HTS systems also utilize Matrigel or other matrices $(19,39)$. Our method's advantage is that it does not involve extracellular matrix utilization and enzymatic treatment during culture and assay, significantly reducing labor requirements and cost. Therefore, it is also relatively easy to be adapted to HTS assay systems and various measurement systems. Furthermore, the absence of enzymatic treatment has the advantage of maintaining cell-to-cell interactions and the conditions of heterogeneous source tumors. However, because the extracellular matrix can act as a scaffold for cells and affect tissue morphogenesis, differentiation, and homeostasis, it is desirable to use extracellular matrix for research purposes.

PDO characteristics are unsuitable for HTS or cell analysis using 96-well or 384-well formats for anti-cancer drugs because these structures display heterogeneous sizes and also form large clusters in culture. Thus, CELL HANDLER ${ }^{\mathrm{TM}}$, which can isolate cell spheroids of a precise size without damage, and NoviSight, which can quantify the specific cells present in cell spheroids with complex structures, were used to improve the accuracy of anti-cancer drug assays and 3D cell analysis using 384-well plates as well as to automate the process. This resulted in uniform cell sizes, and when applied, we succeeded in developing a precise HTS platform using F-PDOs. The assays using F-PDO and hematopoietic tumor-derived F-PDX were performed with high accuracy. In contrast, the solid tumor-derived F-PDX assay did not (data not shown) because it was challenging to mince the solid tumor tissue uniformly. Collecting a large minced tumor tissue using CELL HANDLER ${ }^{\mathrm{TM}}$ was also challenging. By developing a uniform mincing method for tumor tissues and using CELL HANDLER $^{\text {TM }}$ to collect large tissues, we plan to establish a more accurate assay system using solid cancer-derived F-PDX in the future.

In the EGFR inhibitor sensitivity test of lung tumor-derived F-PDOs, those with mutant EGFRs that are clinically sensitive to EGFR inhibitors were more sensitive than the wild type.
F-PDX derived from hematopoietic tumors showed different sensitivity to anti-cancer agents compared with the existing cancer cell lines. Furthermore, F-PDO and F-PDX showed different sensitivities owing to varying patient characteristics. These results suggest that F-PDOs reflect the clinical status of the source tumors in terms of responsiveness to drugs. Therefore, this assay system enables the evaluation of anti-cancer agents under conditions that reflect clinical conditions more accurately than conventional methods do and may be useful in identifying markers that predict the pharmacological effects of anti-cancer drugs.

Several attempts have been made to evaluate immunotherapy potency, particularly the development of patient-derived tumor models, including PDX. However, PDX is not suitable for evaluating tumor immunology and drugs targeting the immune system because of severely immunocompromised host animals. Thus, humanized mice harboring a human immune system have been used, although problems with the graft-versus-host disease severely limit its implementation $(40,41)$. In addition, in vivo culture is hindered by labor and financial burdens due to the lengthy process of establishing tumor engraftment and generating cohorts for experimentation. Thus, we developed an in vitro assay system using F-PDO or F-PDX to evaluate immunotherapy potency. By co-culturing F-PDO and immune cells, cytotoxicity to target tumor cells could be measured in real-time using xCELLigence. In addition, NoviSight enabled us to detect the number of tumor cells that were dying in specific locations in cell clusters. Furthermore, in vitro evaluation of the bispecific antibody could also be performed using hematopoietic tumor-derived F-PDX and immune cells. Compared with the animal model, this system is straightforward and cost-effective to develop and can evaluate immunotherapy potency.

Finally, this study demonstrated that F-PDO and F-PDX models, which retain tumor tissue characteristics, are superior in evaluating potential novel cancer immunotherapies and anti-cancer drugs. Therefore, they present opportunities for drug assessment and advances in personalized medicine approaches. Although the assay system developed by us is suitable for the initial screening of drugs, it does not reproduce the tumor microenvironment and thus cannot evaluate the efficacy of drugs in vivo. Therefore, we will construct an in vitro system that can mimic human tumor tissue by co-culturing with vascular endothelial cells and other stromal cells or organ-on-a-chip technology in the future. Our ultimate goal is to develop a system that can mimic cancer tissues in vivo and evaluate the efficacy of anti-cancer drugs without animal models.

\section{Acknowledgements}

The authors would like to thank Dr Goto Hiroaki (Kanagawa Children's Medical Center, Yokohama, Japan) and Dr Chitose Ogawa (National Cancer Center, Tokyo, Japan) in the Japanese Pediatric Cancer Group for providing ALL cells from the patients.

\section{Funding}

The present study was supported by grants from the Translational Research Programs from Fukushima Prefecture. 


\section{Availability of data and materials}

The datasets used and/or analyzed during the current study are available from the corresponding author on reasonable request.

\section{Authors' contributions}

MT, SW, KK, HS and KS conceptualized and designed the experiments. NT, AH, GH, HT, HH, YD, HI, KT, KG, NO and SM performed the experiments. NT, AH, HT, GH, HH and MT analyzed the data and wrote the paper. MT revised the paper. MT and NT confirmed the authenticity of the data. All authors read and approved the final manuscript.

\section{Ethics approval and consent to participate}

All experiments involving materials derived from humans were performed following the guidelines of the Declaration of Helsinki and were approved in advance by the Ethics Committee of the Fukushima Medical University (Fukushima, Japan; approval nos. 1953 and 2192; approval dates March 18, 2020, and May 26, 2016, respectively). The participants provided written informed consent. Furthermore, animal experiments were performed with the approval of the Institutional Animal Care and Use Committee of Fukushima Medical University (approval nos. 27011, 29035 and 2019027; approval dates April 1,2015, April 1, 2017, and April 1, 2019, respectively).

\section{Patient consent for publication}

Not applicable.

\section{Competing interests}

The authors declare that they have no competing interests.

\section{References}

1. Sharma SV, Haber DA and Settleman J: Cell line-based platforms to evaluate the therapeutic efficacy of candidate anticancer agents. Nat Rev Cancer 10: 241-253, 2010.

2. Shamir ER and Ewald AJ: Three-dimensional organotypic culture: Experimental models of mammalian biology and disease. Nat Rev Mol Cell Biol 15: 647-664, 2014.

3. Arrowsmith $\mathrm{J}$ and Miller P: Trial watch: Phase II and phase III attrition rates 2011-2012. Nat Rev Drug Discov 12: 569, 2013.

4. Arrowsmith J: Trial watch: Phase II failures: 2008-2010. Nat Rev Drug Discov 10: 328-329, 2011.

5. DiMasi JA, Reichert JM, Feldman L and Malins A: Clinical approval success rates for investigational cancer drugs. Clin Pharmacol Ther 94: 329-335, 2013.

6. Tentler JJ, Tan AC, Weekes CD, Jimeno A, Leong S, Pitts TM, Arcaroli JJ, Messersmith WA and Eckhardt SG: Patient-derived tumour xenografts as models for oncology drug development. Nat Rev Clin Oncol 9: 338-350, 2012.

7. Siolas D and Hannon GJ: Patient-derived tumor xenografts: Transforming clinical samples into mouse models. Cancer Res 73: 5315-5319, 2013.

8. Rosfjord E, Lucas J, Li G and Gerber HP: Advances in patient-derived tumor xenografts: From target identification to predicting clinical response rates in oncology. Biochem Pharmacol 91: 135-143, 2014.

9. Hidalgo M, Amant F, Biankin AV, Budinská E, Byrne AT, Caldas C, Clarke RB, de Jong S, Jonkers J, Mælandsmo GM, et al: Patient-derived xenograft models: An emerging platform for translational cancer research. Cancer Discov 4: 998-1013, 2014.
10. Gao H, Korn JM, Ferretti S, Monahan JE, Wang Y, Singh M, Zhang C, Schnell C, Yang G, Zhang Y, et al: High-throughput screening using patient-derived tumor xenografts to predict clinical trial drug response. Nat Med 21: 1318-1325, 2015.

11. Maru Y and Hippo Y: Current status of patient-derived ovarian cancer models. Cells 8: 505, 2019.

12. Weeber F, Ooft SN, Dijkstra KK and Voest EE: Tumor organoids as a pre-clinical cancer model for drug discovery. Cell Chem Biol 24: 1092-1100, 2017.

13. Crespo M, Vilar E, Tsai SY, Chang K, Amin S, Srinivasan T, Zhang T, Pipalia NH, Chen HJ, Witherspoon M, et al: Colonic organoids derived from human induced pluripotent stem cells for modeling colorectal cancer and drug testing. Nat Med 23: 878-884, 2017.

14. Sato T, Stange DE, Ferrante M, Vries RG, Van Es JH, Van den Brink S, Van Houdt WJ, Pronk A, Van Gorp J, Siersema PD, et al: Long-term expansion of epithelial organoids from human colon, adenoma, adenocarcinoma, and Barrett's epithelium. Gastroenterology 141: 1762-1772, 2011.

15. van de Wetering M, Francies HE, Francis JM, Bounova G, Iorio F, Pronk A, van Houdt W, van Gorp J, Taylor-Weiner A, Kester L, et al: Prospective derivation of a living organoid biobank of colorectal cancer patients. Cell 161: 933-945, 2015.

16. Boj SF, Hwang CI, Baker LA, Chio II, Engle DD, Corbo V, Jager M, Ponz-Sarvise M, Tiriac H, Spector MS, et al: Organoid models of human and mouse ductal pancreatic cancer. Cell 160: 324-338, 2015.

17. Gao D, Vela I, Sboner A, Iaquinta PJ, Karthaus WR, Gopalan A, Dowling C, Wanjala JN, Undvall EA, Arora VK, et al: Organoid cultures derived from patients with advanced prostate cancer. Cell 159: 176-187, 2014.

18. Girda E, Huang EC, Leiserowitz GS and Smith LH: The use of endometrial cancer patient-derived organoid culture for drug sensitivity testing is feasible. Int J Gynecol Cancer 27: 1701-1707, 2017.

19. Broutier L, Mastrogiovanni G, Verstegen MM, Francies HE, GavarróLM, Bradshaw CR, Allen GE, Arnes-Benito R, Sidorova O, Gaspersz MP, et al: Human primary liver cancer-derived organoid cultures for disease modeling and drug screening. Nat Med 23: 1424-1435, 2017.

20. Pauli C, Hopkins BD, Prandi D, Shaw R, Fedrizzi T, Sboner A, Sailer V, Augello M, Puca L, Rosati R, et al: Personalized in vitro and in vivo cancer models to guide precision medicine. Cancer Discov 7: 462-477, 2017.

21. Kondo J,Endo H, Okuyama H, Ishikawa O, Iishi H, Tsujii M, Ohue M and Inoue M: Retaining cell-cell contact enables preparation and culture of spheroids composed of pure primary cancer cells from colorectal cancer. Proc Natl Acad Sci USA 108: 6235-6240, 2011.

22. Yoshida T, Okuyama H, Endo H and Inoue M: Spheroid cultures of primary urothelial cancer cells: Cancer tissue-originated spheroid (CTOS) method. Methods Mol Biol 1655: 145-153, 2018.

23. Meijer TG, Naipal KA, Jager A and van Gent DC: Ex vivo tumor culture systems for functional drug testing and therapy response prediction. Future Sci OA 3: FSO190, 2017.

24. Inoue A, Deem AK, Kopetz S, Heffernan TP, Draetta GF and Carugo A: Current and future horizons of patient-derived xenograft models in colorectal cancer translational research. Cancers (Basel) 11: 1321, 2019.

25. Hum NR, Sebastian A, Gilmore SF, He W, Martin KA, Hinckley A, Dubbin KR, Moya ML, Wheeler EK, Coleman MA, et al: Comparative molecular analysis of cancer behavior cultured in vitro, in vivo, and ex vivo. Cancers (Basel) 12: 690, 2020.

26. Tamura H, Higa A, Hoshi H, Hiyama G, Takahashi N, Ryufuku M, Morisawa G, Yanagisawa Y, Ito E, Imai JI, et al: Evaluation of anticancer agents using patient-derived tumor organoids characteristically similar to source tissues. Oncol Rep 40: 635-646, 2018.

27. Takahashi N, Hoshi H, Higa A, Hiyama G, Tamura H, Ogawa M, Takagi K, Goda K, Okabe N, Muto S, et al: An in vitro system for evaluating molecular targeted drugs using lung patient-derived tumor organoids. Cells 8: 481, 2019.

28. Pan C, Liu H, Robins E, Song W, Liu D, Li Z and Zheng L: Next-generation immuno-oncology agents: Current momentum shifts in cancer immunotherapy. J Hematol Oncol 13: 29, 2020.

29. Hegde PS and Chen DS: Top 10 challenges in cancer immunotherapy. Immunity 52: 17-35, 2020.

30. Farkona S, Diamandis EP and Blasutig IM: Cancer immunotherapy: The beginning of the end of cancer? BMC Med 14: 73, 2016.

31. Andrews MC and Wargo JA: Immunotherapy resistance: The answers lie ahead - not in front - of us. J Immunother Cancer 5: $10,2017$. 
32. Xu H, Lyu X, Yi M, Zhao W, Song Y and Wu K: Organoid technology and applications in cancer research. J Hematol Oncol 11: $116,2018$.

33. Cerignoli F, Abassi YA, Lamarche BJ, Guenther G, Santa Ana D, Guimet D, Zhang W, Zhang J and Xi B: In vitro immunotherapy potency assays using real-time cell analysis. PLoS One 13: e0193498, 2018.

34. Ito M, Hiramatsu H, Kobayashi K, Suzue K, Kawahata M, Hioki K, Ueyama Y, Koyanagi Y, Sugamura K, Tsuji K, et al: NOD/SCID/gamma(c)(null) mouse: An excellent recipient mouse model for engraftment of human cells. Blood 100: 3175-3182, 2002.

35. Zhang JH, Chung TD and Oldenburg KR: A simple statistical parameter for use in evaluation and validation of high throughput screening assays. J Biomol Screen 4: 67-73, 1999.

36. Shah R and Lester JF: Tyrosine Kinase Inhibitors for the treatment of EGFR mutation-positive non-small-cell lung cancer: A clash of the generations. Clin Lung Cancer 21: e216-e228, 2020.

37. Salih HR, Antropius H, Gieseke F, Lutz SZ, Kanz L, Rammensee HG and Steinle A: Functional expression and release of ligands for the activating immunoreceptor NKG2D in leukemia. Blood 102: 1389-1396, 2003.
38. Palechor-Ceron N, Krawczyk E, Dakic A, Simic V, Yuan H, Blancato J, Wang W, Hubbard F, Zheng YL, Dan H, et al: Conditional reprogramming for patient-derived cancer models and next-generation living biobanks. Cells 8: 1327, 2019.

39. Du Y, Li X, Niu Q, Mo X, Qui M, Ma T, Kuo CJ and Fu H: Development of a miniaturized 3D organoid culture platform for ultra-high-throughput screening. J Mol Cell Biol 12: 630-643, 2020.

40. Cassidy JW, Caldas C and Bruna A: Maintaining tumor heterogeneity in patient-derived tumor xenografts. Cancer Res 75: 2963-2968, 2015.

41. Shultz LD, Brehm MA, Garcia-Martinez JV and Greiner DL: Humanized mice for immune system investigation: Progress, promise and challenges. Nat Rev Immunol 12: 786-798, 2012.

(i) (9) This work is licensed under a Creative Commons Attribution-NonCommercial-NoDerivatives 4.0 International (CC BY-NC-ND 4.0) License. 